\title{
A Sea-change or a Swamp? New Spaces for Voluntary Sector Engagement in Governance in the UK
}

\author{
Marilyn Taylor, with Gary Craig, Surya Monro, Tessa Parkes, \\ Diane Warburton and Mick Wilkinson
}

\section{Introduction}

On coming to power in 1997, the New Labour government in the UK promoted a new approach to welfare, which would avoid the excesses of both the state and the market. This 'third way' (Giddens 1998) represented a move from a 'contract culture to a partnership culture' and offered new opportunities for voluntary associations. While much attention was focused on their role in the delivery of public services, the 'third way' also provided new spaces for voluntary and community organisations (VCOs) to act as vehicles for citizen, community and consumer participation in policy making. ${ }^{1}$ This article explores the dimensions and dynamics of the new spaces that have opened up in the wake of these policy shifts, and how voluntary and community organisations have responded to them. It draws on research into engagement by VCOs in policy processes at different levels, in political opportunity structures of varying degrees of openness, and in respect of three key policy fields: pollution (environmental policy area); Better Government for Older People and the establishment of a minimum income for pensioners; the National Strategy for Neighbourhood Renewal. ${ }^{2}$ It begins by sketching out the changing role of the voluntary and community sector (VCS) over time, and focuses in on the changes that have been introduced by the New Labour government. It then asks how open the spaces that have been created for voluntary and community involvement in the policy process are, and to whom they are open. It concludes by asking what prospects they hold for the future and the challenges that VCOs face in making these spaces work for them.

\section{The UK voluntary sector in context}

The UK voluntary sector has always been a 'loose and baggy monster' (Kendall and Knapp 1995), with its strength arguably lying in its diversity, combining philanthropy and mutuality, service provision and advocacy, containing organisations right along the spectrum from large bureaucratic, professionalised organisations to small associational networks, with no paid staff. It employs 2 per cent of the UK workforce and contributes 2 per cent of GDP (Kendall and Almond 1999; Jas et al. 2002). Government provides the largest share of its income at 45 per cent, with philanthropy contributing 19 per cent and earned income 36 per cent. Indeed, in recent years, the sector is increasingly referred to as the voluntary and community sector, recognising its variety and acknowledging the different levels of kinds of policy support that may be relevant at different points within the sector.

Over the centuries, the UK voluntary sector has played different roles in welfare. From the early seventeenth century, when charitable law first became systematised, through to the nineteenth century, a dual system of welfare operated in the UK, with voluntary associations operating largely independently to provide for the needs of the "deserving poor". The late nineteenth and early part of the twentieth century saw the gradual entry of the state into welfare, first as regulator, then as funder and eventually as provider, although the pace of change varied between different policy fields. This culminated in the establishment of a comprehensive welfare state in the 1940s, in which 
the state assumed the major responsibility for welfare. During this time the voluntary sector evolved new roles, providing services that were complementary to state welfare and developing an advocacy role, providing a voice for those whose needs were not adequately met, acting as a watchdog on state services and a channel for citizen voice.

The introduction of markets into welfare in the 1980s, under the Thatcher regime, offered an enhanced role for the voluntary sector in delivery of public services, on contract to state purchasers. Income from government increased by 40 per cent between 1991 and 2001, outpacing total income growth in the economy. The greatest growth was in social care and social housing (Kendall 2003). Many within the sector were, however, concerned about the impact of the "contract culture" on the diversity of roles the sector was playing, as well as on autonomy. With the advent of welfare markets, many felt that this advocacy role would be compromised, because of the strings that a government purchaser might be expected to apply to contract funding and because, under a neo-liberal welfare regime, government would not support advocacy, it would be seen as distorting the market. However, a role in policy development was not ruled out totally. In the social care field, for example, voluntary sector service providers were involved in joint planning at local level, while a range of voluntary organisations, including self-help and user-based organisations, were seen as a route for ensuring that consumer voice was heard. Similarly in the urban regeneration field, the Conservative government of the early 1990s began to make some housing funding dependent on the involvement of tenants' organisations and also began to encourage partnership working, although voluntary and community organisations largely remained on the margins of these partnerships.

\section{New spaces}

Since the election of the New Labour government in 1997, most organisations would agree that there has been a "sea-change" in relation to the policy process. The emphasis on partnership and participation that has so far characterised this administration means that government has provided new political spaces. As one person from a Black and minority ethnic group put it, "previously, there was the sort of regime in which you would have to push the door in order to enter the room - now the door is open and you can walk in'. In addition, the movement of key personnel from the voluntary to the statutory sector at national and regional level, sometimes through recruitment, but also through a series of secondments, along with the establishment of a number of advisory groups drawn from all sectors, has made the policy community increasingly porous.

The growing significance of the VCS as the "third" sector has been acknowledged in countless government documents and institutionalised in the agreement of a "compact" of principles and codes of practice to govern relationships between the public sector and the VCS. The contribution of the sector to policy as well as service delivery is recognised in a third document, through an acknowledgement of the right of VCOs to criticise government policy, even when in receipt of government funding (The Home Office 1998). As one civil servant told us, 'generally speaking, government wouldn't think about preparing a document and not consulting the key voluntary organisations'. Two major government reviews, the Treasury's review of the role of the voluntary and community sectors in service delivery (known as the 'Cross-Cutting Review') and the review of the legal and regulatory framework for charities and other not-for-profit bodies, underline the importance of the VCS in the policy process. The first acknowledges the importance of involving VCOs in the planning as well as the delivery of services; the second refers to the need to enable charities to advocate effectively. Most recently, the Home Office has introduced a civil renewal agenda which recognises that, 'the freedom of citizens can only be truly realised if they are enabled to participate constructively in the decisions which affect their lives' (Blunkett 2003: 3).

The opening up of the policy process has been particularly marked in the government's policies to address social exclusion in the most disadvantaged neighbourhoods in the UK. During a two-year consultation period, 18 Policy Action Teams (PATs) were set up to look at different aspects of neighbourhood exclusion, bringing leading practitioners, academics, intermediary bodies and "social entrepreneurs" together to identify the lessons from the past and come up with proposals for the future. The PATs visited and invited evidence from neighbourhoods across the country. Once the PATs had made their recommendations, a draft national strategy was published and put out for 
consultation, and a key intermediary body within the VCS was commissioned to coordinate the response. The strategy was then finalised in 2001 and a Community Forum, involving people living and working in disadvantaged neighbourhoods, has been set up to advise the Neighbourhood Renewal Unit on implementation issues. Neighbourhood activists are also being trained to provide consultancy to other neighbourhoods.

In setting up the National Strategy, the Prime Minister has consistently argued that communities must be at the heart of renewal. In an often-cited statement, he argued that 'too much has been imposed from above, when experience shows that success depends on communities themselves having the power and taking the responsibility to make things better' (SEU 1998: 7). In a parallel initiative, the New Deal for Communities, residents in 39 of the most disadvantaged areas have been encouraged to take a lead in drawing up and implementing tenyear strategies to tackle their disadvantage. Time and resources have been committed from the development stage through to implementation, to support their involvement. As part of the National Strategy for Neighbourhood Renewal (NSNR), local strategic partnerships (LSPs) have been set up in the 88 authorities that have the most disadvantaged neighbourhoods within them. These new LSPs are to draw up neighbourhood renewal strategies and also to participate in the development of community strategies by the local authority. They are expected to demonstrate community involvement in order to become accredited by government and so draw down the funding set aside for them. Crucially, government has recognised that communities need support to get involved. A Community Empowerment Fund has been set up to provide resources directly to Community Empowerment Networks in each of the 88 areas. The importance of this new initiative has perhaps been underlined by the fact that many other local authorities are setting them up as well, even though they are not eligible for targeted funding.

While the increased openness of policy has been most marked in neighbourhood renewal, it has not been confined to this policy arena. In the field of older people's welfare, a programme to encourage a more holistic approach to issues affecting older people, Better Government for Older People (BGOP), while less ambitious than the NSNR, also committed itself to giving older people a voice. It was preceded by a series of Listening to Older People events, of which a civil servant in our research said,

Instead of having Ministers sitting in their Whitehall departments in their plush private offices and getting the occasional correspondence from this person or that person, otherwise picking up on the real issues that concern people through constituency surgeries or through Parliament, the idea was that we should take Ministers out and about and get them to meet people that perhaps normally wouldn't have the chance to meet a Minister and give them the chance to put their points to Whitehall directly.

When BGOP was introduced, its Steering Committee set up a national advisory group made up of older people. A civil servant involved reported:

For example, we went away for a couple of days before the programme's recommendations were drafted with representatives of older people themselves, who played a big part in the way the recommendations were shaped. The SG may have been going in a similar direction, but it was very valuable to have the older people's input as well, given that they were - while not the most representative group, certainly more representative than the Steering Committee.

In the environmental field, Local Agenda 21 had already provided new spaces for local engagement prior to the election of New Labour, although the leverage that VCOs had in these spaces was variable. Under New Labour, there were no environmental initiatives parallel to the NSNR or BGOP. However, the restructuring of central government departments, with the creation of a new Department of the Environment, Food and Rural Affairs (DEFRA) was generally held to be a positive move. The new Department was seen as much more open to the VCS than its predecessors, with regular round tables, expert groups and advisory groups.

\section{Scope for influence?}

There are three ways of looking at the new spaces that government has provided for citizen engagement. One, which is the most optimistic perspective, is to acknowledge that there has indeed been a sea-change and that these new spaces are characterised by a new governance culture in which 
power is genuinely shared and created. A second, more pessimistic view, would see these new spaces as sites of co-option, where existing forms of power are reproduced through rules of engagement which privilege state actors. A third would be more guardedly optimistic and would see windows of opportunity in these new spaces, despite the dangers that lurk there. Thus Sidney Tarrow has argued, 'the opening of opportunities produces external resources for people who lack internal ones, openings where there were only walls before, alliances that did not previously seem possible' (Tarrow 1994: 99).

Our research found some support for the third option. In the neighbourhood renewal field, for example, even where local authorities are still resistant, as they are in a number of cases, the drive from the centre has strengthened the hands of allies within the public sector and forced the doubters to the table. Some of our respondents described themselves as 'knocking at an open door'. With players on both sides uncertain about the new rules of engagement in these spaces, there are major new opportunities to exploit this uncertainty. Some argued that now the tap had been turned on it would be impossible to turn off.

However, the downside of this is that, often, it is unclear who has responsibility for an issue; the new order can be quite "swampy" and "messy". And, state systems have reacted to this messiness by imposing new forms of order. Initial experience suggests that the rules of engagement are still dictated by state actors, who determine the rules of the game. Furthermore, despite the rhetoric of decentralisation, central government's emphasis on performance management now means that control is being increasingly centralised through national targets and performance management systems. The new managerialism and the audit culture which pervade the public sector have reinstituted central, top-down control in less visible forms and this threatens to take the politics out of the public sphere and policy making altogether (Taylor 2003). The scope for influence is dictated by "what counts" and community partners can easily become mired in operational rather than strategic issues.

Second, there are clearly "no-go" areas, even in the new policy environment, the economic growth agenda, the new managerialism with its performance targets, and the emphasis on "delivery". There was a strong message in our research that the Treasury controls the agenda, its tentacles appeared to reach across all parts of government, to the extent that even other government departments felt relatively powerless. In our case studies, the issues on which respondents felt they had made least headway were campaigns around benefits such as minimum income for pensioners, or attempts in the neighbourhood renewal field to allow more flexibility around benefits in order to ease the transition into employment, to compensate community Board members or to allow for temporary employment of community members. Campaigns for subsidised residential care for older people had also come up against a brick wall in England, although it met with success in Scotland.

A third barrier is resistance down the line. Whatever the message from the centre about citizen and community participation, practice is variable: both between local authorities and over different policy arenas. While community participants in special initiatives like the New Deal for Communities or Better Government for Older People have gained power and influence within the confines of these initiatives, influence over mainstream services and policy remains frustratingly elusive. Even where there is a will to change, local authorities still lack the capacity or the incentive to respond to community priorities. Local authorities only raise a small proportion of their income directly (some 20 per cent) and they face tight financial constraints on spending from central government. Front-line workers are undervalued. Middle managers feel threatened and squeezed between financial constraints and service-driven targets driven from the centre on the one hand and the new demands that communities should be in control on the other. In these circumstances, one respondent argued, they behave like 'wounded lions', protecting what strength and territory they have left.

Finally, VCOs needed to be alert to the different spaces and rules of engagement that apply at different stages in the policy cycle. Even in the field of neighbourhood renewal, where VCOs felt there was most scope for influence, there was a feeling that government had now done its consultation and was impatient with any criticism. The emphasis was turning to delivery and achieving the forecast spend. There was increasing concern that the windows of opportunity might begin to close; political attention spans tend to be short and, although government committed itself to a long-term agenda in relation to community renewal, for example, respondents 
in this and later studies argued that the concern with delivery was beginning to erode that commitment.

Despite these challenges, however, our respondents still felt, with Tarrow, that there were opportunities for influence. They had allies within government, who saw an opportunity to work with VCOs to challenge centralised agendas and develop new approaches. As one put it,

Even people like me who regard ourselves as specialists, the more we find that we cannot do without people who are working at the sharp edge of policy, these organisations have to have people within their own systems who can deal with the most obscure parts of public policy, because it is so complicated. They are really needed more now than they ever were.

Many could point to small changes and, even when things did not go their way, there was scope for fine-tuning. Thus, for example, older people's organisations stayed at the table even when they failed to win their argument in order to minimise the adverse effects of unsatisfactory policies. Others pointed out that it was necessary to have a long-term perspective. As one respondent from an environmental organisation argued, there was a 'drip, drip effect. What we [environmental organisations] were suggesting ten years ago pops up as government policy now'. Indeed some in the regeneration field argued that the NSNR was a demonstration of this effect, having taken on board much of what VCOs in the field had been arguing for over the years.

\section{Engaging participants}

Barnes et al.'s article in this Bulletin documents the energy, effort and imagination that is going into giving people the opportunity to make their voice heard. New and imaginative forms of consultation are being introduced to try to engage citizens in policy and service delivery. An over-reliance on surveys and focus groups is beginning to give way to more deliberative forms of consultation, which ensure that people have the information on which to make decisions and the opportunity for debate. How widespread these are is less certain. The Neighbourhood Renewal Unit has set up a website on "good practice", which has the capacity to share learning and ideas around consultation (renewal.net). But practice is currently extremely variable across the country and question marks remain over what happens as a result of these exercises. The apathy of which many communities are accused is often a response to past consultation exercises which have been ignored and where there has been no feedback on what has happened to the results. There are also dangers that, the more fashionable they become, the more new participatory methods will be taken "off the shelf", with little understanding of how they need to be implemented and without the skills to make them effective (e.g. see Cooke and Kothari's 2001 critique of participatory appraisal).

There is a sense also that the VCS has been a victim of its own success. The constant flood of consultations, advisory groups, commissions, etc. that NGOs are invited to take part in have real costs in terms of staff resources and of setting and meeting internal targets. This is a particular problem for Black and minority ethnic groups. The Community Empowerment Fund, introduced to ensure community participation in local strategic partnerships (see above), is a significant step forward in supporting the VCS infrastructure, but it is still very limited in scope and only available in the 88 neighbourhood renewal areas. Following the CrossCutting Review (HM Treasury 2002), two further reviews have taken place to address the capacity building and infrastructure agendas within the sector. The results of these reviews were put to consultation towards the end of 2003. Concerns have been expressed that new resources will focus mainly on the sector's service delivery role. However, the Home Office focus on 'civil renewal', although still fairly broadly defined, could help to redress the balance.

\section{From presence to influence}

Maloney et al. (1994) argue that groups can have influence on government if they have something to trade. Government's concern to reach the "real people" on the ground, i.e. those that the government/local government/health authority, etc. could not reach, means that many previously excluded groups now find themselves courted by the decision makers. There is a particularly strong emphasis on reaching Black and minority ethnic groups; government is, for example, resourcing networks at regional level. However, the complexity of many processes means that only those who can hit the ground running can engage. Thus, whilst in theory, Black and minority ethnic groups' organisations are being invited into the new political spaces, the lack of infrastructure and resources to 
represent their very diverse communities often excludes most of them in practice.

Government's emphasis on involving "real people" means that, contrary to expectations, the size of organisation is not always a predictor of influence. Indeed, in the neighbourhood renewal arena, we found considerable suspicion of traditional voluntary organisations in government as well as among community organisations, which meant that some of the more traditional organisations felt they were being sidelined. Government's emphasis on making direct contact with people on the ground therefore meant that traditional insiders could find themselves left out, while those who had previously been excluded from the policy process were facing the same dilemmas as the larger organisations that they would have criticised in the past, trying to balance their new "insider" status with the need to maintain their independence and avoid being co-opted. It has become commonplace to argue that larger voluntary organisations are losing their roots in the sector and becoming incorporated in the state. Nonetheless, some of the larger voluntary organisations were playing an important role in giving smaller groups access to the policy-making arena: providing training for user-based and community organisations who may take a more campaigning stance, and providing "docking points" for smaller organisations which allowed the latter to opt into and out of the formal process on their own terms and without losing their independence (Taylor et al. 2002).

Currencies that opened the door to the policy arena and gave VCOs legitimacy were good quality evidence (especially in the environmental arena), the ability to deliver good policy ideas, and the ability to deliver on the ground (especially in neighbourhood renewal). However, democratic legitimacy, in the sense of having participatory structures and a strong membership, was not always seen as a priority by government actors. Indeed, this was most likely to be raised as an issue, with accusations of unrepresentativeness, when VCOs opposed government agendas (Taylor and Warburton 2003). Building on this theme, some of our VCS respondents were critical of the undue influence exercised by certain "talismanic" individuals at the national level. In neighbourhood renewal, national government has been particularly enamoured with "social entrepreneurs"; in the environment there has been an undue focus, some felt, on certain high-profile individuals. A focus on individuals prevents others from becoming involved and can mean that influence is lost if a particular individual falls out of favour or leaves the arena. In the locality too, there are individuals who are seduced by power. Once they climb Sherry Arnstein's (1971) famous ladder of participation, they pull the ladder up under them.

It became evident that there was an acceptable face of community involvement, and a strong feeling that government still finds it difficult to take criticism. This meant that some organisations were still not welcome in the new political spaces. Government is not particularly sympathetic to adversarial tactics or to trade union styles of campaigning. Government respondents were particularly critical of organisations that persisted in pursuing "lost causes". As one civil servant said:

The more organisations present themselves as part of the solution rather than part of the problem, they're the ones that are likely to influence government and thereby have a larger contribution to make to delivering all this ... There are some organisations that have an impossibilist view of the world, so that it doesn't really matter ... what the policy is or what you do, it's not good enough ... Your 1970s retread community activist isn't someone who is going to influence me...

Some organisations remain outside these new political spaces by choice. Some of our respondents acknowledged that they preferred the "old" ways of working: they knew where they were. They felt the current plethora of partnerships was a distraction, since they did not consider that partners were being involved on an equal basis. There was also some disillusionment with the local strategic partnerships (LSPs). Money for neighbourhood renewal was allocated to local authorities before these new partnerships were up and running and this has, many feel, given the upper hand to the statutory bodies in these new spaces. A certain amount of cynicism has also been engendered by the fact that 87 out of the 88 LSPs were accredited at the first round, despite the fact that evidence of community involvement was supposed to be part of the accreditation process and many VCOs did not feel they have been adequately involved. 
However, others felt that years on the outside had achieved nothing and that they had a responsibility to get into these new spaces and make them work. They were critical of a 'lazy world of caucuses', arguing that:

To not engage would make us appear incapable and unwilling to come forward. It's an open door and we want to take it off its hinges so that no one can put it on again.

A final point concerns other players in these new spaces. Some of our respondents felt that, despite the rhetoric, the focus on the "new" has encouraged government to work with think tanks, which provide a constant flow of new ideas, rather than the VCS which relies more on articulating the views of those who have direct experience of a problem. VCOs have also been highly critical of the influence of business and commerce in the new policy environment. But in some arenas, they have turned to the private sector as allies. All the big environmental organisations now work closely with industry (e.g. on greenfreeze fridges, on environmental guidelines for companies, on the forestry stewardship scheme and others). It is worth noting that, as well as promoting pollution reduction, these relationships with industry have also increased their status with government.

\section{Remaining tensions}

Generally speaking, the above discussion suggests that, while there are still many caveats, there is also much scope for influence in today's new governance spaces in the UK. Thus far, we can agree with Tarrow's earlier analysis of the opportunities that emerge at times of political change. However, our research also suggested that, if they were to operate effectively in these new spaces, VCOs (and their allies within the system) would need to develop considerable political sophistication. The changes that the UK government has made in recent years have cleared some of the undergrowth that frustrated participation in the past, providing longer lead-in times, capacitybuilding resources and resources to the VCS infrastructure. However, removing this undergrowth has exposed a number of inherent tensions in relation to citizen participation that will always need to be addressed, however open the spaces become. These tensions are as relevant to international audiences as they are to the UK.
The first is the tension between cohesion and diversity. Our government respondents were often impatient with the number of different voices they were exposed to on similar issues and clearly preferred the sector to speak with a single voice. But too often the "single voice" means that other voices are being suppressed. In addition, there are many policy trends that divide rather than unite VCOs, not least the highly competitive funding marketplace. Nonetheless, several respondents were critical of the tendency of organisations within the sector to fight each other rather than address wider imbalances of power. The VCS needs to develop the institutional capacity and the infrastructure to allow diversity to be expressed, while finding common cause where this is needed. This in turn requires funding, time and skill. Policy makers for their part need also to develop their own capacity to take account of diversity and difference and to recognise that one size does not fit all.

The second tension is the tension between leadership and participation. Community representatives are often accused of being unrepresentative. There are undoubtedly some community leaders who do not do enough to take their communities with them. But the demands of the system can easily suck people in and away from their community roots. In addition, the number of people who will engage on a sustained basis in these new spaces is always likely to be limited. Expectations need to reflect this and more thought therefore needs to be given to the different levels at which people are likely to participate and how these can most effectively be linked together to ensure accountability from those at the centre to those at the periphery.

Representation is a particularly difficult and contentious issue. On the one hand, some of our government funders were critical of VCOs who were "obsessed" by process; on the other, they were the first to complain if they thought that an organisation was not representative (usually, as suggested earlier, when it opposed the government point of view). Our research led us to question how far representativeness as such was a realisable objective. Many VCS representatives in partnerships find themselves in an impossible "pig in the middle" situation, expected by their constituents to represent community views to partnerships and by official partners to bear the brunt of representing the partnership back to communities and "selling" its 
decisions, even when the community view has not prevailed. It is not a comfortable place to be.

The third tension is the tension between engaging in the policy process and maintaining autonomy. Being invited onto the inside of a policy community can take the sting out of organisations that have been a thorn in government's side. As one of our respondents put it, 'you can't eat something you've been introduced to'. We began our study with the expectation that our organisations could be classified as insiders and outsiders. We found, however, that traditional distinctions had become blurred as government sought to engage with traditionally excluded groups. We also found that many organisations combined insider and outsider status. But this can be a difficult balancing act and requires sophistication. And some traditionally radical VCOs can find they lose support because they are engaged in dialogue with the "enemy". They are seen to have sold out.

The final tension is that between representative and participatory democracy. Not enough thought has gone into the relationship between the two with the result that many politicians are no longer sure of their role and feel threatened by the power that they feel is being given to community representatives. It is this that creates the "wounded lions" at all levels that frustrate the rhetoric from the centre. But this is unlikely to change until new life is breathed into the electoral system and to the formal democratic system.

\section{Conclusion}

So, does the post-1997 experience in the UK encourage optimism or pessimism about the scope for citizen participation, at least as seen from a VCO perspective?

Only the most devout cynic could deny that policy-making spaces are considerably more open to VCS influence in the UK today than they used to be. The research reported in this article found a real sense of optimism amongst many of our respondents. There are still some "no-go" areas but, generally speaking, there is a new energy in many policy arenas with new opportunities and a new interest in the citizen voice. Indeed, our respondents suggested that, having opened these spaces up, it would be very difficult for government to close them again. While it was clear that the sea-change in policy making had become something of a swamp for some players, on the whole, the evidence suggests that VCOs can learn and are learning to operate effectively in these new spaces.

However, this optimism is tempered by concern about quite how open these spaces are, or will remain. As we have seen, public sector actors have not all embraced the opportunities presented by these new spaces and many still enter them reluctantly and defend their corners assiduously. Many of the VCOs in our study felt that, although they now had much greater "voice", they were still unsure about what was heard and therefore whether they had much more power. In addition, there is some concern over the capacity of political timescales and the current focus on "delivery" to accommodate the length of time that real participation takes. Already, by the time of our research, some VCOs felt that the initial momentum was slowing, that most of their influence was now at the implementation end of the policy process and there were few strong and sustained impacts in terms of policy change. Our research also suggested that, however strong the commitment, operating successfully in these new spaces would not only depend on how open government was prepared to be. It would also depend crucially on the capacity of all involved to learn how to resolve the inherent tensions that will always exist within these new spaces.

It seems therefore that there are genuine new spaces and opportunities but that negotiating them will remain risky and challenging. It remains to be seen what the longer-term prognosis will be. We still know too little about the impact of VCO participation in these new spaces at national and local level and there has been remarkably little evaluation of the more general policy role played by VCOs and the impact of their different strategies. But the dialogue represented in this Bulletin offers a way forward. Recent years have seen an encouraging willingness in the UK to look beyond its borders for ideas and learning about participation and especially to the South, on the part of government as well as VCOs. Transnational links and networks between North and South also offer the external resources and opportunities for alliances of which Tarrow spoke in the reference cited earlier in this article, and communications technology means these links extend well beyond the larger and more well-established organisations. If VCOs in the UK are to negotiate these new spaces effectively, this kind of "globalisation from below" may provide a powerful new dimension on which to draw. 


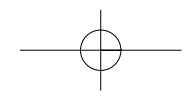

New Spaces for Voluntary Sector Engagement in Governance in the UK

\section{Notes}

1. In the UK, the term voluntary and community sector is the term most commonly used to describe organisations that in other countries are variously known as NGOs, non-profit organisations and third sector organisations.

2. The research on which this article was based was funded by the Economic and Social Research Council (award

\section{References}

Arnstein, S.R., 1971, 'A ladder of participation in the USA', Journal of the Royal Town Planning Institute, April: 176-82

Blunkett, D., 2003, Active Citizens, Strong Communities: Progressing Civil Renewal, London: The Home Office

Cooke, B. and Kothari, U., 2001, Participation: The New Tyranny?, London: Zed Books

Giddens, A., 1998, The Third Way: The Renewal of Social Democracy, London: Polity Press

HM Treasury, 2002, The Role of the Voluntary and Community Sector in Service Delivery: A Cross Cutting Review, London: HM Treasury

The Home Office, 1998, The Compact: Getting it Right Together, Cm 4100, London: The Home Office

Jas, P., Wilding, K., Wainwright, S., Passey, A. and Hems, L., 2002, The UK Voluntary Sector Almanac, London: NCVO Publications

Kendall, J., 2003, The Voluntary Sector: Comparative Perspectives in the UK, London: Routledge

Kendall, J. and Almond, S., 1999, 'United Kingdom', in L. Salamon, H. Anheier, R. List, S. Toepler, W. Sokolowski et al. (eds), Global Civil Society: Dimensions of the Non-profit Sector, Baltimore, MD: The Johns Hopkins Center for Civil Society Studies
L215252049) as part of the Democracy and Participation Programme. Information about the study can be found on the ESRC website (www.regard.ac.uk) and an interim and final summary of the research is also available from the authors.
Kendall, J. and Knapp, M., 1995, 'A Loose and Baggy Monster: Boundaries, Definitions and Typologies', in J. Davis Smith, C. Rochester and R. Hedley (eds), An Introduction to the Voluntary Sector, London: Routledge

Maloney, W.J., Jordan, G. and McLaughlin, A., 1994, 'Interest groups and public policy: the insider/outsider model revisited', Journal of Public Policy, Vol 14 No 1: 17-38

Social Exclusion Unit (SEU), 1998, Bringing Britain Together: A National Strategy for Neighbourhood Renewal, Cm 4045, London: The Stationery Office

Tarrow, S., 1994, Power in Movement: Social Movements, Collective Action and Politics, Cambridge: Cambridge University Press

Taylor, M., 2003, Public Policy in the Community, London: Palgrave

Taylor, M. and Warburton, D., 2003, 'Legitimacy and the role of UK third sector organizations in the policy process', Voluntas, Vol 14 No 3: 321-38

Taylor, M., Craig, G. and Wilkinson, M., 2002, 'Cooption or empowerment? The changing relationship between the state and the voluntary and community sectors', Local Governance, Vol 28 No 1: 1-11 